(again from a friend or parent). It may be an attention-seeking device (if his complaints cause anxiety and consternation in his parents), an escape device (from arithmetic or troubles resulting from inadequately prepared homework), or be due to feelings of insecurity arising from unkindness or excessive strictness at home or school. The family doctor is in the best position to elucidate the causative factors, though he should bear in mind that a child who has 10 attacks of abdominal pain of emotional origin may still develop acute appendicitis or other acute abdominal condition-the diagnosis is not necessarily the same every time.

Treatment is difficult. It includes reassurance that there is no organic disease, the reduction or removal of stress where possible, advice about the parental attitude to the symptoms (or to any disease), with special regard to the importance of avoiding suggestion of symptoms, anxiety about them, or any of the factors which may lead to psychogenic pains. But the treatment decidedly does not include purgatives, sedatives, tranquillizers, or antidepressants; and antispasmodics are apparently of no avail.

\section{Syphilitic Lymphadenitis}

Syphilis can still play strange tricks on clinicians, and clinical diagnosis may be anything but easy. Quite apart from the extraordinary variations shown in symptoms and signs, the moral stigma which still attaches to the condition acts as a barrier to awareness, resulting from an instinctive but false conviction that this cannot be an infection of people of good standing. Even so, modern diagnostic methods are so accurate and so easy to apply that it is surprising to hear of cases in which the pathologist has made the diagnosis by section of lymphatic nodes. R. J. Hartsock and colleagues ${ }^{1}$ found that syphilis had not been suspected in three out of four cases of luetic lymphadenitis from which material was examined at the U.S. Armed Forces Institute of Pathology during the years 1965 and 1966.

In reviewing the material at the institute they found an additional 16 cases in which Treponema pallidum had been identified in lymph nodes. The nodes had been removed from the inguinal region in 17 cases, from axillae in 2 , from the neck in 1 , and from the occipital region in 1. The histological changes showed considerable variations. Of the inguinal nodes 14 had varying degrees of chronic inflammation and extensive fibrosis of capsular and pericapsular areas; sheets of plasma cells in the interfollicular, capsular, and pericapsular areas; vascular changes, such, as phlebitis and endarteritis; and follicular hyperplasia. It was thought that this combination of findings, though not specific for syphilitic lymphadenitis, was sufficiently distinctive to suggest the possibility in the differential diagnosis. Treponemes were found in all these lymph nodes. Other findings were variable numbers of polymorphonuclear leucocytes between the follicles and in the sinuses. A distinctive feature was the degree of inflammation and fibrosis of the capsular and pericapsular tissues, which was usually greater in these specimens than in non-syphilitic lymph nodes.

The lymph nodes removed from axillary, cervical, and occipital regions showed a non-specific follicular hyperplasia which did not suggest the diagnosis of syphilis, but the patients had positive serological tests for the disease, and sections showed treponemes in the walls of blood vessels and

1 Hartsock, R. J., Halling, L. W., and King, F. M., American fournal of Clinical Pathology, 1970, 53, 304. in one case in the germinal centres. An inguinal lymphatic node from one patient showed follicular hyperplasia with numerous non-caseating granulomata in and around germinal centres and also multiple foci of organizing suppurative inflammation. Treponemes were identified in the granulomata, and the authors believed that these appearances represented part of the tuberculoid reaction which can occur in syphilis. Five other inguinal nodes showed tuberculoid reactions, characterized by organized collections of histiocytes, frequently associated with giant cells of the Langhans type. Five lymph nodes in the series showed foci of suppurative inflammation, but treponemes were identified both in the walls and in the necrotic centres of these abscesses. No other causative agent was detected after careful investigation.

In one case, believed to be of early primary syphilis, the lymph node showed diffuse hyperplasia with dilated sinuses. There were only a few plasma cells and minimal inflammation of the capsule. The cellular response consisted mainly of lymphocytes and reticular lymphoblasts. Treponemes were demonstrated in the walls of the blood vessels and of the subcapsular sinuses. These changes possibly represent the earliest histological response to syphilitic infection.

Study of the clinical records of the 20 patients showed that nine of them complained of a painful mass in the inguinal region, though the complaint of pain in these cases is usually regarded as unusual. Six of the patients were submitted to surgical procedures because the diagnosis of incarcerated hernia could not be excluded; only three of these patients were known to have syphilis before the operation was undertaken. Apart from incarcerated hernia, early diagnoses included tuberculosis, glandular fever, Hodgkin's disease, malignant lymphoma, undescended testicle, lymphogranuloma venereum, and granuloma inguinale. The final conclusion was that 9 patients had primary and 11 secondary syphilis. Thus it seems that this disease is still a considerable problem for the diagnostician.

\section{Infected Feeding-stuffs}

Two substantial problems are associated with the highprotein dehydrated foods supplied to animals. One is related to the use of antibiotics in feeding-stuffs and the danger of bacterial resistance, both direct and transferred. Much publicity has already been given to this hazard. ${ }^{1}$ The second is that salmonellae and perhaps other pathogens may lurk in the finished products.

The public health is in danger when animals excreting salmonellae are slaughtered and processed under conditions which allow the spread, survival, and multiplication of the organisms in carcass meat, poultry, offal, mince-meat, and sausage skins. The hazards to those who handle the contaminated materials during manufacture, in the shop, and at home are undoubted. Though cooking should destroy salmonellae in meat and poultry products, safety from heat treatment is not always assured. Furthermore contamination from hands, surfaces, utensils, cloths, and the equipment used in preparation for cooking may be readily passed to foods which are not cooked or require only light cooking, or it may be

1 Joint Committee on the Use of Antibiotics in Animal Husbandry and Veterinary Medicine, Report, Cmnd. 4190. London, H.M.S.O., 1969 2 Harvey, R. W. S., and Price, T. H., Fournal of Hygiene, 1967, 65, 237.

3 Harvey, R. W. S., and Price, T. H., Fournal of Hygiene, 1967, 65, 423.

- Harvey, R. W. S., and Price, T. H., Fournal of Hygiene, 1968, 66, 377 
passed back to the original product when cooked. Both imported and home-produced materials such as bone meal, meat meal, and fish meal (including pellets) are frequently found to be contaminated with salmonellae. The more infected the ingredients, the more likely is the finished product to be infected. This is not necessarily because the organisms survive the heat treatment of processing, though this can happen, but because insufficient care may be taken to avoid contamination of the finished product by the raw materials.

Evidence is growing that when flocks and herds are fed on feeding-stuffs free from salmonellae the excretion of these organisms ceases or at least falls. The Food and Drugs Act does not cover the care of such feeding-stuffs, so that the examination of samples has been possible only through the co-operation of the industry, whose members are anxious to ensure a safe product. Some countries-for example, in Scandinavia-legislate for terminal heat treatment of imported feeding-stuffs found positive for salmonellae, and they claim to have a low incidence of salmonellosis in the population.

In Great Britain waves of human infection by salmonellae of identifiable serotypes follow the introduction of feedingstuffs contaminated with the same serotypes. It is equally true that only certain of the many serotypes found in feeding-stuffs can be isolated from the animals eating them. Techniques for the isolation of salmonellae may be imperfect, though that of R. W. S. Harvey and T. H. Price has yielded excellent results. For the first time Salmonella typhimurium has been isolated frequently from feeding-stuffs, and even Salm. dublin has been found. ${ }^{2} 4$ Endemic serotypes such as Salm. dublin in cattle, Salm. pullorum and Salm. gallinarum in poultry, and Salm. cholerae-suis in pigs have their own secure position in the animal body, and Salm. typhimurium is particularly well adjusted to the intestinal tract of man and animals, but there are many other serotypes which flare up in man owing indirectly to infection from animal feeds. They may die away again or remain endemic.

Human excreters in the kitchen are more often than not the victims of the food they handle. So also are the rats and mice which live on infected food. The root of the problem is the raw food, and it ought to be presented in a safer condition to factories, shops, and homes.

\section{Accident and Emergency Services}

For at least ten years a radical reorganization of our accident and emergency services has been widely recognized to be needed. Eight years ago the Platt Report spoke of a pressing need to review, reorganize, and extend the services to deal adequately with all types of injury, ${ }^{1}$ yet a report published this week concludes that progress has been very disappointing. ${ }^{2}$

This new report was produced by a working party of the Accident Services Review Committee, under the chairmanship of Sir Henry Osmond-Clarke. Against a background of deterioration in the recruitment of staff and the poor standards of accommodation of many departments it emphasizes the importance of taking a broader view of accidents. It draws attention to the needs of commuting and holiday populations as well as aspects such as the prevention of accidents and rehabilitation. Good communications are clearly of the utmost importance, yet in practice they are often poor, and, for example, direct radiotelephone links with the ambulance services are still not universal. The report describes the secretarial help available at present as "without exception ... inadequate," and suggests that when the nursing services are reorganized on the lines recommended by the Salmon Report ${ }^{3}$ there may be fewer experienced nurses willing to be in charge of a casualty department.

When the objectives are so clear, why has so little been achieved in modernizing our accident services? The report points out that other and newer specialties have been given higher priorities. At the same time, as Mr. A. E. Bremner points out in a letter at.p. 113 of this week's B.M. F., the accident and emergency services still do not offer any real prospect of a career in the specialty. Junior staff cannot be expected to take up appointments in a field in which there is no obvious future. Though some accident departments have made definite advances-such as radio links with ambulance services, taking part in the training of ambulance staff, and liaison schemes with other hospital departments over problems such as physiotherapy and rehabilitation - the list of advertisements for vacant posts in accident and emergency departments continues to grow.

The working party found that consultant participation in the accident and emergency services was "generally inadequate." The consultant nominally in charge was usually a general or an orthopaedic surgeon, who attended the department to do an outpatient clinic. One possible solution to ending the second-class status might be to have a career grade supporting the consultant, with the opportunity for suitably experienced staff to achieve consultant status in the accident and emergency department itself. This might do much to improve the attractions of the service and encourage recruitment to it.

One of the common objections to appointing consultant casualty officers has been that trauma involves more than one specialty. Nevertheless, in hospital practice few of the established specialties can now deal in isolation with the investigation and treatment of any individual patient. Moreover, improvements in status and career prospects might themselves solve many presentday problems, such as the need for secretarial help, ready contact with other hospital departments, and the ability to approach related authorities, such as the ambulance service, on an equal footing. At the same time, with supervision and training recruitment of junior staff would become easier.

The "casual attender" is referred to in the report as being a major problem to accident departments in some areas, and undoubtedly some of the pressure on these departments results from their misuse by the public. This raises the question not only of education of the public but of the relation between general practitioners and the accident services. The report refers to the successful use of family doctors in one hospital and certainly more experiments are needed to determine the extent of the co-operation needed between these two important sections of the Health Service.

The need to do something about the accident and emergency services is urgent. More patients are seen every year, yet departments are closing while ambulance journeys are lengthening. That the situation is near crisis point is clear when there has been a suggestion recently that casualty departments should be kept open without medical staff immediately available. Surely it is better to attract doctors to work in this clinically rewarding field by making it attractive in terms of long-term prospects.

\footnotetext{
1 Central Health Services Council, Accident and Emergency Services,

London, H.M.S.O., 1962. Report of a Working Party, London, H.M.S.O. 1970.

Report of a Working Party, London, H.M.S.O., 1970.
Ministry of Health, Senior Nursing Staff Structure, London, H.M.S.O., 1966.

4 Burkitt, R. T., British Medical fournal, 1970, 3, 585.
} 